Robinson Jo (Orcid ID: 0000-0001-5652-918X)

Teh Zoe (Orcid ID: 0000-0001-8481-3049)

\title{
Globalization of the \#chatsafe guidelines: Using social media for youth suicide prevention
}

\section{Authors and affiliations:}

Jo Robinson ${ }^{1,2}$, Zoe Teh ${ }^{1,2}$, Michelle Lamblin ${ }^{1,2}$, Nicole T. M. Hill ${ }^{1,2,3}$, Louise La Sala ${ }^{1,2}$, Pinar Thorn ${ }^{1,2}$.

1. Orygen, Parkville, Victoria, Australia

2. Centre for Youth Mental Health, The University of Melbourne, Parkville, Victoria, Australia

3. Telethon Kids Institute, Perth, Western Australia, Australia

\section{Corresponding Author:}

A/Prof. Jo Robinson.

Orygen and the Centre for Youth Mental Health, The University of Melbourne, Australia. 35 Poplar Road, Parkville, 3052, Victoria, Australia.

Ph: +6139342 2866

Email: jo.robinson@orygen.org.au

Article type: Brief report for publication in Early Intervention in Psychiatry

Word count: 1808

Key words: suicide, social media, guidelines, health resource, adolescent

This is the author manuscript accepted for publication and has undergone full peer review but has not been through the copyediting, typesetting, pagination and proofreading process, which may lead to differences between this version and the Version of Record. Please cite this article as doi: 10.1111/eip.13044

This article is protected by copyright. All rights reserved. 


\begin{abstract}
Background

Young people use social media to communicate about suicide, however, they often feel illequipped to share their own experiences or to respond to expressions of risk by others.
\end{abstract}

\title{
Aims
}

To describe the adaptation of the Australian \#chatsafe guidelines for an international audience, and their initial roll out via social media.

\section{Methods}

An online survey $(n=48)$ and two workshops $(n=47)$ conducted between August and December 2019. Thirty-eight countries were represented.

\section{Results}

Minimal adaptation of the Australian guidelines was required however, an abbreviated version and a suite of social media assets were developed. In the 6 weeks following publication the international guidelines were downloaded $~ 4100$ times and the social media content reached over one million young people.

\section{Conclusion}

The fact that the guidelines and campaign content appear to have had such success speaks to the need for young people to feel better equipped to communicate safely about suicide online.

This article is protected by copyright. All rights reserved. 


\section{Introduction}

Suicide is the second leading cause of death in young people aged 15 to 24 years worldwide (Mokdad et al., 2016). Young people frequently use social media to communicate about suicide and although there are multiple benefits to this (Robinson et al., 2016), concerns regarding the potential for harm exist (Luxton, June, \& Fairall, 2012).

To address this, we developed the \#chatsafe guidelines to facilitate safe peer-to-peer communication about suicide online (Robinson et al., 2018). However, because guidelines are not necessarily accessible for young people we also co-designed a 12-week social media campaign with young people, which was shared across Australia in late 2019 and early 2020 (Thorn et al., 2020). Since publication in August 2018, the Australian guidelines have been downloaded over 27,000 times, and the 12-week campaign reached approximately 1.5 million young people.

However, suicide does not just affect young Australians, and in 2019 we adapted the guidelines for the United States and then received funding to adapt the guidelines for an additional 10 regions. The aims of this short report are to describe: 1) the process of adapting the guidelines for these additional 10 regions; and 2) their initial roll out via social media.

\section{Methods}

Data were collected via an online survey and two face-to-face workshops with key stakeholders.

\section{Online survey}

An invitation to take part in the online survey was sent from lead researcher (JR) via email to: 1) youth members of the International Association for Youth Mental Health; 2) members of the suicide clusters and media interest subgroups of the International Association of Suicide Prevention; and 3) Facebook’s Suicide and Self-injury Advisory group.

This article is protected by copyright. All rights reserved. 
The online survey was administered via Qualtrics between August and December 2019. It was structured around the five sections of the Australian guidelines (see Table 1). As per the original Delphi study used to create the Australian guidelines, participants were asked to rate each component in the guidelines based on how 'important' and how 'appropriate' they considered it to be for their region, using a five-point Likert scale ranging from 'should not be included' to 'essential'. Participants were also invited to provide additional comments and considerations on each section of the guidelines regarding adapting the guidelines for their region.

\section{Face-to-face workshops}

Two international workshops were conducted by the lead researcher (JR). The first was conducted at the International Association of Suicide Prevention World Congress, in Derry, in September 2019. The second was conducted with Facebook’s Suicide and Self-injury Advisory Group, in New York, in October 2019.

At each workshop participants were asked to discuss: 1) what was currently missing from the guidelines; 2) what a condensed version of the guidelines should include; 3) cultural considerations surrounding suicide, online memorialization, and self-care; and 4) to make suggestions regarding the development of 'templates' to assist a young person to share their own story about suicidality and to help a friend expressing suicide risk online.

Ethical approval was obtained from the University of Melbourne Psychology Health and Applied Sciences Human Ethics Sub-Committee (ID: 1749618).

\section{Results}

Survey findings

Forty-eight people from 26 countries completed the survey. Of them, 23.7\% $(n=14)$ identified as a young person (i.e., aged $<25$ years), and the remaining $76.0 \%$ identified as either a suicide prevention expert ( $n=38 ; 90.5 \%)$ or a communications professional $(n=3$; 7.1\%). Almost all participants reported using social media $(n=45 ; 93.8 \%)$. Half of the 
participants, reported that their country of residence had guidelines designed to assist mainstream media communicate safely about suicide.

Most participants reported that each section of the current guidelines was both important and appropriate to include in the international adaptations. See Table 1.

\section{[Insert Table 1 about here]}

Participants also made some suggestions as to how they thought the guidelines could be improved. The most common comment was that the guidelines were considered to be too long and participants recommended that an abbreviated version be developed. Related to this, they suggested that a suite of social media assets be developed to help disseminate the guidelines, and that partnerships should be developed with local service providers in each region to facilitate this. Several comments were also made relating to cultural considerations in terms of language used to discuss suicide and the self-care strategies recommended in the guidelines. Participants from Canada and New Zealand identified the need for First Nations versions of the guidelines. Participants from both Nigeria and Brazil noted that there are limited services available to help people in times of crisis in their regions, however, that it was still important to convey messages of hope.

\section{Workshop findings}

Forty-seven people, from 21 countries, participated in the workshops. Overall findings suggested that the guidelines were considered to be comprehensive, but (as per the survey findings) participants suggested an abbreviated version be made available. Several suggestions were made regarding how the guidelines could be made more culturally appropriate for different communities such as including country-specific resources and contact information, and community-specific self-care strategies.

Finally, participants were asked to make suggestions regarding the development of 'templates' to assist a young person to share their own story and to help a friend. A number 
of suggestions were made relating to language and format. In terms of language, this was strongly dependent on the particular region. For example, some cultures and languages do not have direct translations for the words "died by suicide”, or they use alternative expressions omitting the term suicide such as "died by tragic circumstances”. With regard to format, participants suggested that the templates use a combination of text, animation and video, or handwritten 'low-resolution' images.

\section{Guideline development and roll out}

Following the consultations, 10 regions were identified to receive adapted versions of the guidelines. The regions were selected in partnership with the funder on the basis of survey responses, rates of youth suicide, and capacity/willingness to partner. The 10 selected regions were: Brazil, Finland, Hong Kong, Mexico, Nigeria, Norway, Singapore, South Korea, Sweden, and the United Kingdom.

Based on the study findings, minimal adaptation of the guidelines was required, however, where necessary they were translated into the local language, and in all cases details of local youth-friendly helplines replaced the equivalent Australian information. An abbreviated version of the guidelines was also developed which condensed the content into '10 Top Tips'. Finally, a suite of social media assets was developed for each partner region to assist with the uptake and accessibility of the guidelines. Where possible, this was done in partnership with young people from the local area, but when this was not possible, adapted versions of the Australian content was provided. See Figure 1. Further resources, including the 'templates' for sharing a personal story and supporting a friend at risk are currently in development.

[Insert Figure 1 about here]

The international guidelines were published on the Orygen website in May 2020 (Orygen, 2020) with links from the website of each of the partner organisations, and from the Facebook Safety Centre. In the six weeks following publication they have been downloaded just over 4,100 times and the social media content has reached over one million young people 
( $\mathrm{n}=1,069,126)$ via a combination of targeted advertising and organic sharing by the partners on Instagram, Facebook and Twitter. The countries in which the guidelines and campaign content appear to have had most traction are Finland, Mexico and Sweden respectively. See Table 2. Additional metrics are available on request.

\section{[Insert Table 2 about here]}

\section{Discussion}

This short report has described the development of the \#chatsafe guidelines for 10 regions across the world. The guidelines were developed following consultation with stakeholders from 38 countries. Other than translation, minimal adaptation to the Australian guidelines was required. It was however noted that the guidelines were too long to be accessible for young people, and therefore, an abbreviated resource was also developed (i.e., "Top 10 Tips). As in Australia, a suite of social media assets was provided to assist with the dissemination of the guidelines to young people in each region.

In the six weeks following publication, the international guidelines were downloaded just over 4,100 times and the social media content has reached over one million young people across the partner regions. The guidelines and associated content have had similar uptake in Australia, and we think that there are probably multiple reasons for their success. Youth suicide rates are increasing both in Australia (ABS, 2019) and elsewhere in the world (Bould, Mars, Moran, Biddle, \& Gunnell, 2019; Mahase, 2000). It is well documented that young people are often reluctant to seek professional help (Michelmore \& Hindley, 2012), and when they do, they are often met with an inadequate response (Bridge, Marcus, \& Olfson, 2012). In contrast, social media is seen as both accessible and acceptable (Robinson et al., 2016), but young people are often afraid to share their own feelings of suicidality or to respond to a friend at risk, for fear of doing harm (Thorn et al., 2020). This is possibly because until now, the dominant narrative has been to discourage open communication about suicide, particularly online, due to concerns of imitative behaviour (Luxton et al., 2012). The fact that 
the \#chatsafe intervention appears to have had such uptake speaks to the need for young people across the globe to feel better equipped to have these sensitive conversations safely.

\section{Limitations}

This study is not without its limitations. Firstly, because we needed to keep the overall content of the guidelines evidence-informed and true to the original Delphi study, not all suggestions made by participants could be accommodated, in particular those that were highly specific to one culture or community. However, the guidelines will be subject to a further Delphi study in early 2021 and the additional suggestions will form part of the consensus process. Funding is also being sought to develop versions of the guidelines for First Nation communities. Second, different regions had different levels of capacity to roll out the campaign content via social media, which likely explains the variation in uptake across the different regions. Related to this not all regions provided data on campaign reach, hence the reported figure is likely an underestimate. Third, stakeholders were self-selected and recruited from convenience samples of key peak bodies and industry partners, and as such may not be fully representative. Finally, it was hoped that each partner agency would be able to work with local young people to codesign the social media content. However, because the study was conducted during the COVID-19 pandemic this was only possible in four of the participating regions.

\section{Conclusions}

This is the first study worldwide to develop a series of international guidelines to facilitate safe peer-to-peer communication about suicide on social media. The impact of the \#chatsafe intervention is currently being evaluated in Australia, but it is hoped that together the guidelines and associated campaign content will help young people from across the globe feel better equipped to share their own experiences of suicidality and to respond to expressions of risk by others.

\section{Acknowledgments}

This article is protected by copyright. All rights reserved. 
The study received funding from Facebook. The original \#chatsafe guidelines were developed with funding from the Australian Government, under the National Suicide Prevention Leadership and Support Program. JR is funded by a National Health and Medical Research Council Career Development Fellowship (ID: 1142348). NH is funded by an Australian Rotary Health PhD Partnership scholarship.

The authors would also like to thank all those who participated in the survey and the workshops and the following partner organisations in each region: Caritas (Hong Kong); Instituto Vita Alere (Brazil); Isabel Ayuda para la Vida AC (Mexico); Mentally Aware Nigeria (Nigeria); Miele (Finland); Mind (Sweden); Mindlink, Gwangju Bukgu Community Mental Health Centre, and the Korean Suicide Prevention Centre (Korea); National Centre for Suicide Research and Prevention (Norway); Samarians of Singapore (Singapore); Samaritans (UK). United States partners were the Jed Foundation and Stanford University.

\section{Conflict of Interests}

The authors report no conflicts of interest.

\section{Data sharing}

The data that support the findings of this study are available from the corresponding author upon reasonable request.

\section{References}

Australian Bureau of Statistics. (2019). 3303.0 - Causes of Death, Australia, 2018. Retrieved from https://www.abs.gov.au/ausstats/abs@.nsf/mf/3303.0.

Bould, H., Mars, B., Moran, P., Biddle, L., Gunnell, D. (2019). Rising suicide rates among adolescents in England and Wales, Lancet, 394(10193), 116-117, doi: 10.1016/S0140-6736(19)31102-X.

This article is protected by copyright. All rights reserved. 
Bridge, J. A., Marcus, S. C., \& Olfson, M. (2012). Outpatient care of young people after emergency treatment of deliberate self-harm, Journal of the American Academy of Child and Adolescent Psychiatry, 51(2), 213-222. doi: 10.1016/j.jaac.2011.11.002

The Jed Foundation. (2019). Orygen and The Jed Foundation launch \#chatsafe in the US., first evidence-based guidelines to help young people talk safely online about suicide. https://www.jedfoundation.org/orygen-and-the-jed-foundation-launch-chatsafe-in-theu-s-first-evidence-based-guidelines-to-help-young-people-talk-safely-online-aboutsuicide/

Luxton, D.D., June, J.D., \& Fairall, J.M. (2012). Social media and suicide: A public health perspective. American Journal of Public Health, 102(Suppl 2), S195-S200. doi: 10.2105/AJPH.2011.300608.

Mahase, E. (2019). US suicide rates in young people are highest since 2000, BMJ, 365, I4289. doi: 10.1136/bmj.l4289.

Michelmore, L., \& Hindley, P. (2012). Help-seeking for suicidal thoughts and self-harm in young people: A systematic review, Suicide and Life-Threatening Behavior, 42(5), 507-524. doi: 10.1111/j.1943-278X.2012.00108.x.

Mokodad, A. H., Forouzanfar, M. H., Daoud, F., Mokdad, A. A., El Bcheraoui, C., MoradiLakeh, M., ... Murray, C. J. L. (2016). Global burden of diseases, injuries, and risk factors for young people’s health during 1990-2013: A systematic analysis for the global burden of disease study 2013, Lancet, 387(10036), 2383-2401. doi: 10.1016/S0140-6736(16)00648-6.

Orygen. (2020). Chatsafe: Tools and tips to help young people communicate safely online about suicide. Retrieved from https://www.orygen.org.au/chatsafe.

Thorn, P., Hill, N. T. M., Lamblin, M., Teh, Z., Battersby-Coulter, R., Rice, S., ... Robinson, J. (2020). Developing a suicide prevention social media campaign with young people (the \#chatsafe project): Co-design approach, JMIR Mental Health, 7(5), e17520. doi: $10.2196 / 17520$.

Robinson, J., Cox, G., Bailey, E., Hetrick, S., Rodrigues, M., Fisher, S., \& Herman, H. (2016). Social media and suicide prevention: A systematic review. Early Intervention in Psychiatry, 10(2), 103-121. doi: 10.1111/eip.12229.

This article is protected by copyright. All rights reserved. 
Robinson, J., Hill, N. T., Thorn, P., Battersby, R., Teh, Z., Reavley, N. J., ... Skehan, J. (2018). The \#chatsafe project. Developing guidelines to help young people communicate safely about suicide on social media: A Delphi study. PLoS One, 13(11): e0206584. doi: 10.1371/journal.pone.0206584.

This article is protected by copyright. All rights reserved. 
Figure 1: Examples of the international social media content

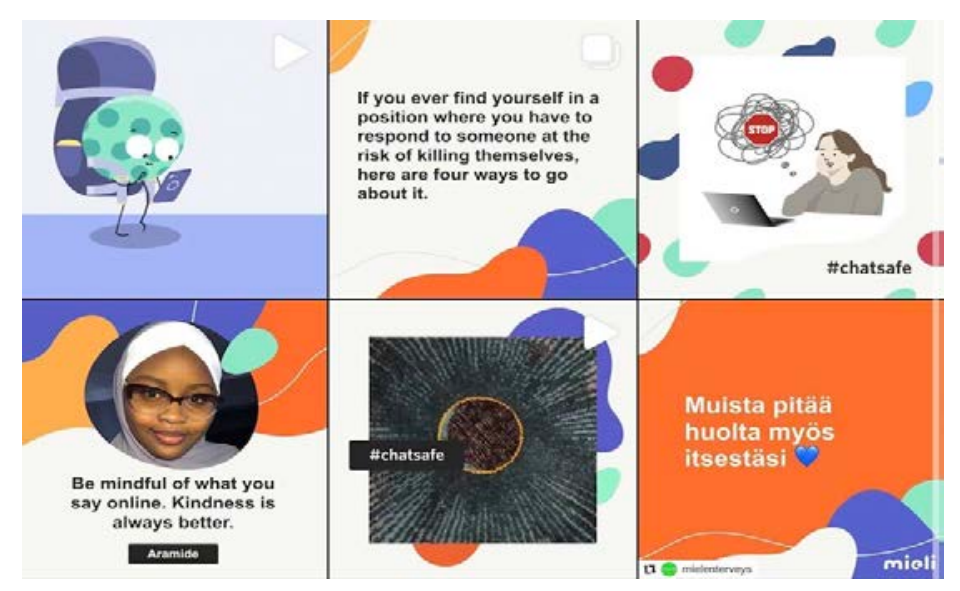

This article is protected by copyright. All rights reserved. 


\section{Tables}

Table 1: Importance and appropriateness of each section of the guidelines for an international audience $(N=48)$

\begin{tabular}{|ll|c|c|}
\hline \multicolumn{2}{|l|}{ Guideline section } & $\begin{array}{c}\text { Importance } \\
\text { \% (n) }\end{array}$ & $\begin{array}{c}\text { Appropriateness } \\
\text { \% (n) }\end{array}$ \\
\hline 1. & Before you post anything about suicide online & $89.5 \%(32)$ & $84.6 \%(31)$ \\
\hline 2. & $\begin{array}{l}\text { Sharing your own thoughts, feelings or experiences } \\
\text { with suicidal behavior online }\end{array}$ & $87.6 \%(34)$ & $82.9 \%(29)$ \\
\hline 3. & $\begin{array}{l}\text { Communicating about someone you know who is } \\
\text { affected by suicidal thoughts, feelings or behaviours }\end{array}$ & $92.9 \%(33)$ & $92.9 \%(32)$ \\
\hline 4. & Responding to someone who may be suicidal & $95.0 \%(33)$ & $91.4 \%(32)$ \\
\hline 5. & $\begin{array}{l}\text { Memorial websites, pages and closed groups to } \\
\text { honour the deceased }\end{array}$ & $88.2 \%(30)$ & $88.2 \%(30)$ \\
\hline
\end{tabular}

Note. Ratings were calculated based on the average of all responses for each subtheme.

Table 2: Campaign reach and guideline access

\begin{tabular}{|l|c|c|c|c|}
\hline Country & \multicolumn{2}{|c|}{ Campaign reach } & \multicolumn{2}{c|}{ Guideline access } \\
\hline Facebook & Partner reach & $\begin{array}{c}\text { Clicks to } \\
\text { guidelines from } \\
\text { campaign content }\end{array}$ & $\begin{array}{c}\text { Guideline } \\
\text { downloads }\end{array}$ \\
\hline Brazil & 37,192 & NA & 1,356 & 144 \\
\hline Finland & 6,522 & 746,455 & 50 & 77 \\
\hline Hong Kong & 13,072 & NA & 226 & 65 \\
\hline Mexico & 106,465 & NA & 1,285 & 210 \\
\hline Nigeria & 40,672 & NA & 1,176 & 1,602 \\
\hline Norway & 8,606 & 15,846 & 71 & 790 \\
\hline Singapore & 6,904 & 13,251 & 152 & 188 \\
\hline South Korea & 5,846 & NA & 121 & 50 \\
\hline Sweden & 9,540 & 55,000 & 76 & 682 \\
\hline $\begin{array}{l}\text { United } \\
\text { Kingdom }\end{array}$ & 3,755 & NA & 61 & 375 \\
\hline Total & $\mathbf{2 3 8 , 5 7 4}$ & $\mathbf{8 3 0 , 5 5 2}$ & $\mathbf{4 , 5 7 4}$ & $\mathbf{4 , 1 8 3}$ \\
\hline
\end{tabular}

Reach: Number of individuals the content reached

NA: Data not available 


\section{University Library}

\section{- M M N E R VA A gateway to Melbourne's research publications}

Minerva Access is the Institutional Repository of The University of Melbourne

Author/s:

Robinson, J;Teh, Z;Lamblin, M;Hill, NTM;La Sala, L;Thorn, P

Title:

Globalization of the \#chatsafe guidelines: Using social media for youth suicide prevention

Date:

2020-09-15

Citation:

Robinson, J., Teh, Z., Lamblin, M., Hill, N. T. M., La Sala, L. \& Thorn, P. (2020). Globalization of the \#chatsafe guidelines: Using social media for youth suicide prevention. EARLY

INTERVENTION IN PSYCHIATRY, 15 (5), pp.1409-1413. https://doi.org/10.1111/eip.13044.

Persistent Link:

http://hdl.handle.net/11343/276302 